\title{
WILEY-VCH
}

\section{Multifunctional surfaces for improving soft tissue integration}

Adriana Vilaça, Rui M.A. Domingues, Hanna Tiainen, Bárbara B. Mendes, Alejandro Barrantes, Rui L. Reis, Manuela E. Gomes and Manuel Gomez-Florit*

Ms. Adriana Vilaça, Dr. Rui M.A. Domingues, Dr. Bárbara B. Mendes, Prof. Rui L. Reis, Prof. Manuela E. Gomes, Dr. Manuel Gomez-Florit

3B's Research Group - Biomaterials, Biodegradables and Biomimetics, Department of Polymer Engineering, University of Minho, Headquarters of the European Institute of Excellence on Tissue Engineering and Regenerative Medicine, Avepark - Parque de Ciência e Tecnologia, Zona Industrial da Gandra, 4805-017 Barco, Guimarães, Portugal.

ICVS/3B’s-PT Associated Laboratory, 4805-017 Braga/Guimarães, Portugal.

E-mail: mgflorit@i3bs.uminho.pt

Dr. Hanna Tiainen

Department of Biomaterials, Institute of Clinical Dentistry, University of Oslo, P.O. box 1109 Blindern, 0317 Oslo, Norway.

Dr. Alejandro Barrantes

Oral Research Laboratory, Institute of Clinical Dentistry, University of Oslo, P.O. Box 1143 Blindern, 0317 Oslo, Norway

Keywords: titanium implants, cellulose nanocrystals, soft tissue attachment, platelet lysate, bacteria, macrophages, fibroblasts. 


\section{WILEY-VCH}

\section{Abstract}

Metallic implants are widely used in diverse clinical applications to aid in recovery from lesions or to replace native hard tissues. However, the lack of integration of metallic surfaces with soft tissue interfaces causes the occurrence of biomaterial-associated infections, which can trigger a complicated inflammatory response and, ultimately, implant failure. Here, we propose a multifunctional implant surface showing nanoscale anisotropy, based on the controlled deposition of cellulose nanocrystals (CNC), and biological activity derived from platelet lysate (PL) biomolecules sequestered and presented on CNC surface. The anisotropic radial nanopatterns are produced on polished titanium surfaces by spin coating $\mathrm{CNC}$ at high speed. Furthermore, $\mathrm{CNC}$ surface chemistry allows to further sequester and form a coating of bioactive molecules derived from PL. The surface anisotropy provided by $\mathrm{CNC}$ guides fibroblasts growth and alignment up to 14 days of culture. Moreover, PL-derived biomolecules polarize macrophages towards the M2-like anti-inflammatory phenotype. These results suggest that the developed multifunctional surfaces could promote soft tissue integration to metallic implants and, at the same time, prevent bacterial invasion, tissue inflammation, and failure of biomedical metallic implants. 


\section{WILEY-VCH}

\section{Introduction}

The replacement of hard tissues in orthopedic and dental applications commonly relies on the use of metallic implants due to their good biocompatibility, good mechanical properties, excellent corrosion resistance and ability to directly contact bone (also called osseointegration). ${ }^{[1]}$ These include perforating metal implants, artificial limbs, external fracture fixators, bone-anchored hearing aids, and dental implants, which are anchored in the hard tissue (bone) and extend through the soft tissue, either temporarily or permanently, to aid in recovery from lesions or to replace native hard tissues. ${ }^{[2]}$ However, the integration of metallic implants with soft tissue interfaces is challenging. A characteristic of many native tissues, including soft tissues around teeth and skin, is an anisotropic organization. ${ }^{[3]}$ In teeth, this is a key feature to maintain a high mechanical resistance and a stable soft tissue around them, preventing bacterial penetration. ${ }^{[4]}$ This lack of an effective soft tissue integration causes the occurrence of biomaterial-associated infections, since bacteria can enter the implantation site and form a biofilm on the implant surface. ${ }^{[5]}$ For example, the infection rate of osseointegrated arm prostheses and dental implants is $38 \%{ }^{[6]}$ and $20-47 \%,{ }^{[7,8]}$ respectively. In addition, this triggers a persistent immune activation in the areas surrounding metal implants, creating a state of chronic inflammation. ${ }^{[8]}$

A wide variety of strategies are being tested to manipulate the bioactivity (e.g. surface topography and chemistry) of metallic surfaces. ${ }^{[9-11]}$ Surfaces modified with nanoscale topographical features, by the introduction of patterning, functionalization and/or molecular grafting, are able to induce changes in cell adhesion, growth, differentiation and production of extracellular matrix $(\mathrm{ECM}) \cdot{ }^{[9,12,13]}$ In previous studies, stem cells cultured on a substrate of aligned carbon nanotubes exhibited directional growth and osteogenic differentiation due to the enhanced cytoskeletal tension. ${ }^{[14]}$ As well, glass surfaces coated with a monolayer of oriented rod-shaped cellulose nanocrystals (CNC), the "nature's carbon nanotubes", were able to induce the differentiation of myoblasts, which produced radial patterns of myotubes. ${ }^{[15,16]}$ On the other 


\section{WILEY-VCH}

hand, the chemical modification of surfaces with biomolecules (e.g. growth factors, proteins or polymers) has been used to obtain bioactive implant surfaces capable of inducing specific cellular responses. ${ }^{[9-11]}$ Nevertheless, these monofunctional strategies do not tackle the complex scenario associated with the lack of soft tissue integration. Therefore, metallic implants at the soft tissue interface would benefit from engineered surfaces with multifunctional properties able to promote the ordered organization of soft tissues and, at the same time, prevent bacterial invasion, tissue inflammation, loosening and failure of the implants.

We previously showed that CNC possess a versatile surface chemistry able to sequester in their protein corona biomolecules from platelet lysate (PL), ${ }^{[17]}$ a milieu of biological elements (growth factors, cytokines, antimicrobial peptides and scaffolding proteins) known to modulate different cell functions, including adhesion, proliferation and differentiation. ${ }^{[18]}$ Actually, the use of platelet derived products, such as platelet-rich-plasma (PRP) and PL, is gaining increasing attention in clinical settings. ${ }^{[18-20]}$ Recently, PRP has been incorporated in dental implant surgery as an interesting strategy to increase Ti bioactivity. ${ }^{[21,22]}$ This procedure has achieved promising results with improved bone regeneration and $\mathrm{Ti}$ osseointegration process. ${ }^{[20]}$ As well, PL has been used to create cell instructive nanocoatings ${ }^{[23,24]}$ and membranes for periodontal regeneration. ${ }^{[25]}$ Additionally, these PL membranes exhibited an antibacterial effect by reducing the adhesion, proliferation and biofilm formation of Staphylococcus aureus (S. aureus). ${ }^{[26]}$ However, poor characterization, low mechanical competence and burst release of bioactive molecules from platelet derived biomaterials have limited their clinical translation. ${ }^{[18]}$

We hypothesized that the combination of surface anisotropy created by CNC together with the sequestration of bioactive molecules from PL on an implant surface would allow the development of multifunctional coatings that could improve soft tissue integration and regeneration, decrease bacterial colonization and, therefore, increase implants success. For this, anisotropic nanopatterns were developed based on the controlled immobilization of CNC on 


\section{WILEY-VCH}

titanium surfaces. Furthermore, we used CNC versatile surface chemistry to sequester and present bioactive molecules from PL. Then, the ability of these surfaces to guide cell behavior was tested using human gingival fibroblasts. The bioactivity of the surfaces was further tested using a macrophages polarization assay.

\section{Results and discussion}

\subsection{Controlling the orientation of $\mathrm{CNC}$ to produce anisotropic nanopatterns on implant surfaces}

Nanocelluloses are a class of natural origin nanomaterials that have been increasingly considered for groundbreaking applications in materials science. ${ }^{[27]}$ These materials include $\mathrm{CNC}$, rod-shaped nanoparticles produced from cellulose fibers that present outstanding strength and stiffness, high aspect ratio, convenient surface chemistry and high biocompatibility. ${ }^{[28,29]}$ We obtained CNC by the typical sulfuric acid hydrolysis of microcrystalline cellulose derived from wood pulp. ${ }^{[30]}$ The produced $\mathrm{CNC}$ exhibited the characteristic rod-shaped morphology (Figure S1, Supporting Information), with an average length of $188 \pm 69 \mathrm{~nm}$ and height of $4 \pm$ $2 \mathrm{~nm}$, in agreement with previous works. ${ }^{[17,31]}$

Leveraging on the rod morphology of $\mathrm{CNC}$, we aimed to develop metallic surfaces showing anisotropic and isotropic bioinstructive nanopatterns to guide cell growth and lead to a superior and more predictable soft tissue integration. Inspired by strategies reported elsewhere, ${ }^{[15,16]}$ we used spin-coating to align $\mathrm{CNC}$ and create nanopatterned surfaces. The production of the $\mathrm{CNC}$ nanopatterns was first tested and optimized on glass coverslips (Figure S2 and S3, Supporting Information). After optimization of the spin-coating parameters, CNC nanopatterns were recreated on coin-shaped titanium (Ti) surfaces (Figure 1). Despite some irregularities present on mirror-polished Ti surfaces (Figure S4, Supporting Information), the aligned and random CNC nanopatterns could be replicated on the surface of a relevant biomedical material typically used in metallic implants. The CNC adsorption on Ti surfaces 


\section{WILEY-VCH}

was homogeneous and reproducible, producing a layer of staked CNC interspersed with regions of Ti, as observed on AFM images (Figure 1). The effect of spin speed on CNC orientation can be observed in Figure 1a and b. Randomly oriented CNC without any preferential direction were visualized in the surfaces prepared at low speed spin. However, higher CNC orientation, approximately corresponding to the local radial axis of the surface, was observed in the surfaces prepared at high speed spin (Figure 1b), in agreement with previous works that used spincoating to produce oriented composites of tunicin cellulose on optical glass. ${ }^{[15,16]}$ It is likely that $\mathrm{CNC}$ alignment is a result of several simultaneous physical effects during spinning. First, the higher spin speed $(6000 \mathrm{rpm})$ created enough momentum to align the main axis of rod-shaped $\mathrm{CNC}$ in the radial direction, minimizing the opposition to the existing centrifugal force, as previously shown. ${ }^{[15,16]}$ Second, it has been previously reported that $\mathrm{CNC}$ alignment in radial direction arises from the viscous shear as the suspension flows outward during spin coating. ${ }^{[32]}$

In order to confirm the differences on the relative orientation of the $\mathrm{CNC}$, directional analysis of AFM images was performed. Figure 1c and 1d show representative histograms of CNC directionality on either the center or the border of the random and aligned surfaces, respectively. While CNC orientation on the surfaces prepared using low spin speed presented a multimodal flat distribution, surfaces prepared using high spin speed exhibited on the border of the samples a unimodal nanoparticle orientation with a distribution centered in a single peaked histogram. These data were further confirmed by Gaussian fitting the distribution curves of the replicate samples, which showed that full width at half medium (FWHM) values of aligned surfaces were significantly lower $\left(\mathrm{FWHM}=55 \pm 32.3^{\circ}\right)$ compared with the random surfaces $\left(\mathrm{FWHM} \approx 180^{\circ}\right)$, indicating a high degree of elements orientation on analyzed images (Figure 1e). Thus, although a perfect CNC orientation was not achieved, the cell-friendly and easily-scalable conditions ${ }^{[33]}$ make spin coating a potential tool to produce CNC-based nanopatterned and biocompatible surfaces. Nevertheless, this method could be difficult to 


\section{WILEY-VCH}

implement on implants with complex shapes, and non-shear based methods to align CNC, e.g. based on electrical or magnetic fields, ${ }^{[33]}$ could be better suited for this purpose.
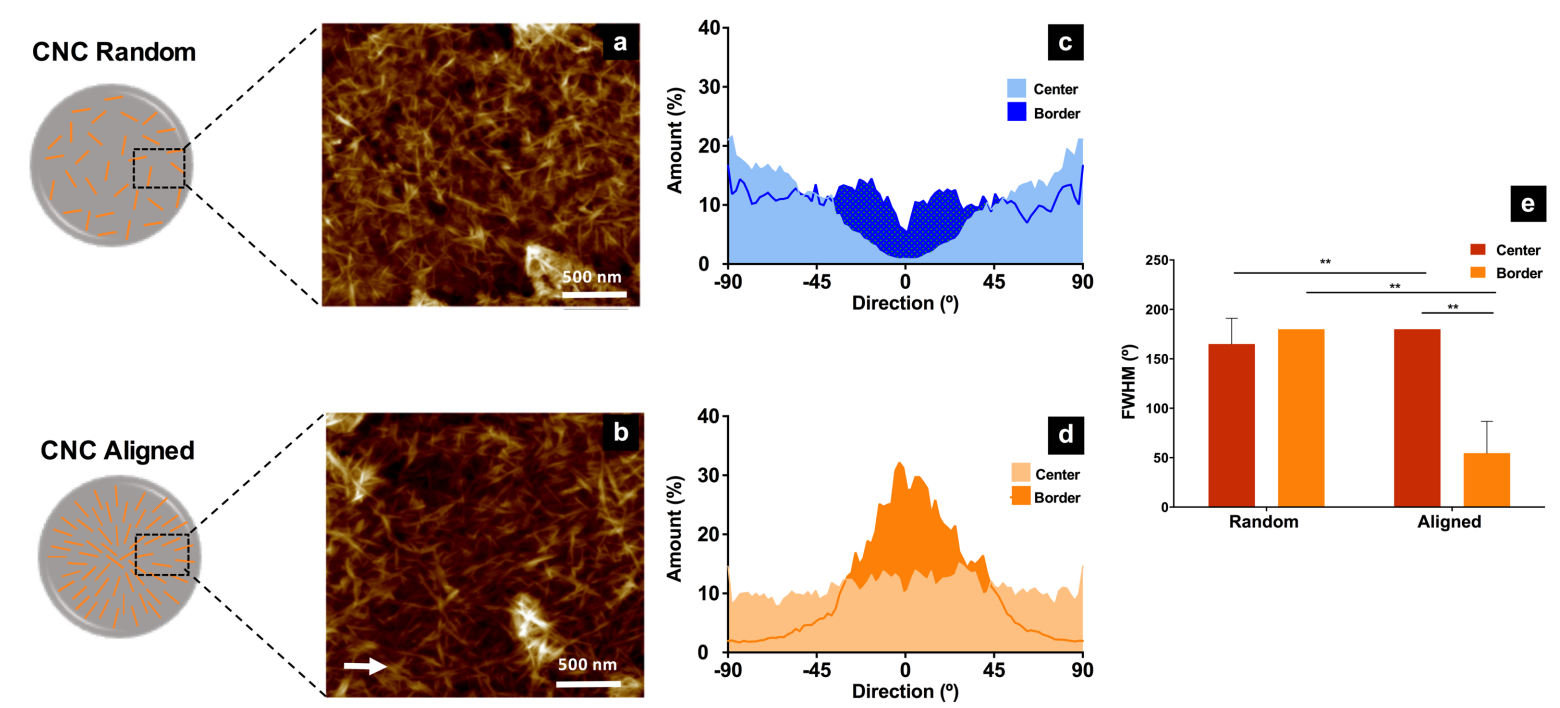

Figure 1. Characterization of the $\mathrm{CNC}$ orientation on $\mathrm{Ti}$ nanocoated surfaces. (a) AFM topography image of random sample on the border of the surface. (b) AFM topography image of an aligned sample on the border of the surface. The arrow indicates the approximate local radial axis on that part of the surface. (c) Directionality histogram of CNC orientation at both center and border of the random surfaces. (d) Directionality histogram of CNC orientation at both center and border of the aligned surfaces. (e) FWHM of the directionality histograms determined by Gaussian fitting of the curves for random and aligned surfaces $(n=3 ; * * p<0.01)$.

\subsection{Biofunctionalization of anisotropic surfaces by sequestering platelet lysate biomolecules}

The typical CNC production method renders nanoparticles that are grafted with sulfate ester groups on their surface (about $292 \pm 5 \mathrm{mmol} / \mathrm{kg}$, obtained from ${ }^{[17]}$ ), imparting a negative surface charge $(-63.03 \pm 0.41 \mathrm{mV})$, in agreement with the literature. ${ }^{[27]}$ In addition, like other nanocelluloses, $\mathrm{CNC}$ have an abundance of hydroxyl groups on their surface that are amenable 


\section{WILEY-VCH}

to hydrogen bonding. ${ }^{[27]}$ In a recent study, we showed that $\mathrm{CNC}$ are able to recruit specific biomolecules from a protein pool, in a process that is mainly driven by the non-covalent protein bounding enabled by the nanoparticles surface chemistry. ${ }^{[17]}$ Thus, we hypothesized that we could use these characteristics of $\mathrm{CNC}$ to sequester bioactive molecules on $\mathrm{Ti}$ surfaces, simultaneously having bioinstructive nanopatterns and bioactive nanocoatings in order to promote soft tissue integration. For this, we used platelet lysate (PL) as an inexpensive pool of bioactive molecules capable of improving cell adhesion, modulating inflammation and decreasing bacterial viability. ${ }^{[18]}$

The assembling of PL nanocoating on CNC-coated surfaces was monitored in real time using a QCM-D setup (Figure 2). An initial decrease in frequency and increase in dissipation was observed immediately after the PL solution was injected, indicating an adsorption of PL biomolecules onto the CNC-coated sensors. At this time, there are many free binding sites on the surface, which facilitates a fast adsorption of highly abundant biomolecules ('soft' protein corona) ${ }^{[34]}$ It is worth mentioning that the change in viscosity due to the higher density of the PL solution is partly responsible for the fast change in the curves. ${ }^{[35]}$ In a second phase, a smoother and sustained decrease in the frequency (and increase in the dissipation) was observed. At this point, the lower amount of free binding sites on the surface slows down the adsorption. In addition, biomolecules and biomolecular complexes with higher affinity start to arrive to the surface due to their lower diffusion rate, which also involves the reorganization of the already adsorbed molecules ('hard' protein corona). ${ }^{[34]}$ In summary, the results suggest that a biphasic PL film with a rigid inner layer and viscoelastic outer part (Figure S6, Supporting Information) was formed on the CNC-coated surfaces.

We also analyzed the PL coating stability by flushing the surfaces with PBS (Figure 2). Quantitative analysis of the frequency shifts before and after PBS rinse showed an increase in the frequency $(18 \pm 5 \mathrm{~Hz})$. Although this increase indicates the release of weakly adsorbed PL proteins from the CNC-coated surfaces, ${ }^{[36]}$ around $25 \%$ of the total mass before the PBS 


\section{WILEY-VCH}

washing, the results confirm the presence of strongly adsorbed PL biomolecules on CNC after the PBS washing, in agreement with our previous results using CNC suspensions. ${ }^{[17]}$

Overall, these results suggest that CNC can effectively mediate the sequestration of PL proteins on $\mathrm{Ti} / \mathrm{CNC}$ surfaces. These findings are of significant interest because it represents a straightforward strategy to incorporate bioactivity on the surfaces of metallic implant because it can emulate the role of the ECM on the regulation of PL signaling biomolecules. The dynamic regulation of the sequestration, release, activation, and presentation to cell surface receptors of bioactive molecules is known to be highly relevant for its effective biological signaling, and functional materials recreating the ECM roles on these mechanisms have shown to drastically potential the effects of, for example, of growth factors. ${ }^{[37,38]}$

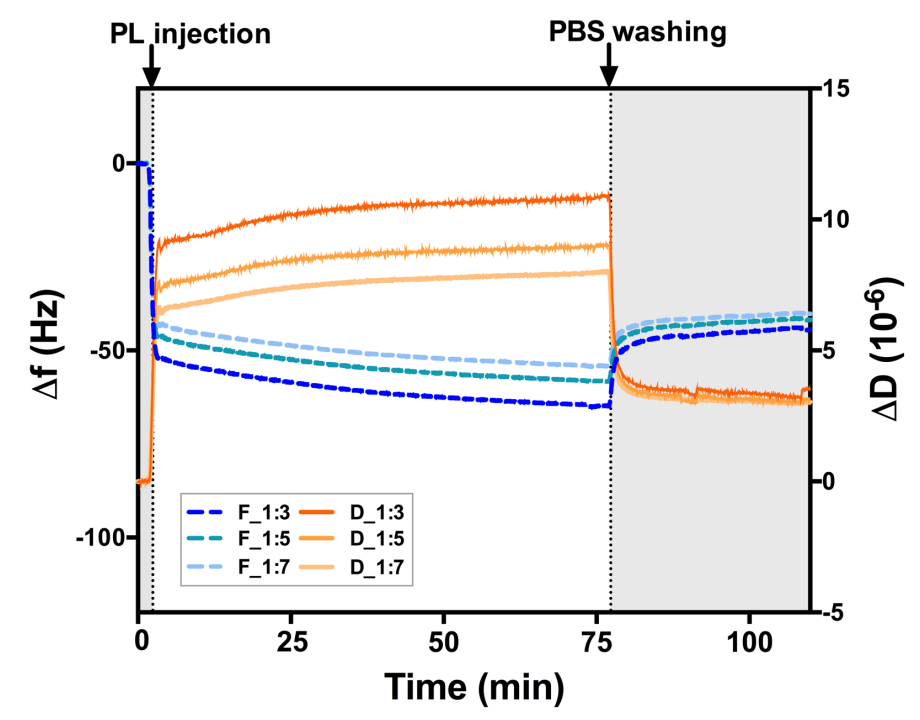

Figure 2. Formation of PL coating by QCM-D. $\Delta \mathrm{f}$-t and $\Delta \mathrm{D}$-t plots showing the third, fifth, and seventh harmonic for PL deposition on the CNC-coated sensor surfaces. Grey areas indicate the flow of PBS while white area indicates flow of PL solution.

Next, we investigated which specific PL proteins are sequestered by CNC surfaces ('hard' biomolecular corona). Using proteomic analysis, the number of proteins identified was 1033 ( $p$ $<0.05 ; \geqslant 2$ unique peptides; in at least 3 replicates; full list of proteins available as Table S1, 


\section{WILEY-VCH}

Supporting Information), which were then classified according to categories of biological process involved (Figure 3a). We found a high percentage of proteins involved in cellular, metabolic, and immune system processes, biological regulation, cellular component organization or biogenesis, and response to stimulus, among others. Interestingly, when proteins were organized by protein class (Figure $3 b$ ), we could observe a high proportion of proteins from the platelet cytoplasm (e.g. enzymes, signaling molecules and cytoskeletal proteins), indicating, as expected, platelet lysis during the freeze/thawing protocol. Also, a high proportion of proteins classes typically related with blood plasma, such as proteins from the defense system, was observed. Overall, these results demonstrate that the multifaceted role of platelet-derived proteins, related to wound healing and cell adhesion, but also to several specialized functions, ${ }^{[39,40]}$ are also reflected on the protein population anchored on CNC surface.

Subsequently, we performed an enrichment test of the identified proteins over the human proteome. We found that several categories related with biological processes involved in cell adhesion, wound healing, inflammatory response and antimicrobial response showed a significant enrichment (Figure 3c). Different structural proteins such as fibronectin and fibrinogen that possess different motifs involved in cell adhesion and regulation of growth factors signaling ${ }^{[41]}$ were detected. Moreover, proteins related to wound healing, such as coagulation factors, or ECM organization (e.g. matrix metalloproteinase-9, tissue inhibitor of matrix metalloproteinases-1) were also identified. Different growth factors, such as transforming growth factor beta-1 (TGFB1), platelet derived growth factor (PDGF) and connective tissue growth factor (CTGF), and signaling molecules, such as platelet factor 4 (PF4), C-C motif chemokine 5 (CCL5) or C-X-C motif chemokine 3 (CXCL3), involved in wound healing and inflammatory response were also present among the proteins sequestered by CNC. Finally, proteins from the antimicrobial humoral response, including different antimicrobial peptides such as lysozyme C (LYZ), cathelicidin (CAMP), dermcidin (DCD), 


\section{WILEY-VCH}

lactotransferrin (LTF), neutrophil defensin 1 (DEFA1B) and cathepsin G (CTSG), also showed a high enrichment ( $\sim 5$-fold; Figure $3 \mathrm{c})$. Antimicrobial peptides are able to kill bacteria by cytoplasmatic membrane permeation and cell lysis ${ }^{[42,43]}$ and have shown potential as antibiofilm agents. ${ }^{[44]}$ Interestingly, the presence of these peptides among the proteins sequestered by $\mathrm{CNC}$ might be related to the reduction in viability found after $S$. aureus incubation on PLbiofunctionalized surfaces, whereas, in opposition, $\mathrm{Ti} / \mathrm{CNC}$ and $\mathrm{Ti}$ surfaces presented a higher number of live bacteria (Figure S7, Supporting Information). Although these results do not allow to conclude the antibacterial properties of the coating, they are in line with previous results using PL-based biomaterials, which exhibited antibacterial effects against different types of bacteria, including S. aureus. ${ }^{[26,45,46]}$ Ultimately, the sequestering and presentation of these proteins to different cells involved in the biological response to biomaterials (e.g. cell adhesion, inflammation) and in antimicrobial response might induce an improved soft tissue integration and decreased bacterial colonization. 


\section{WILEY-VCH}

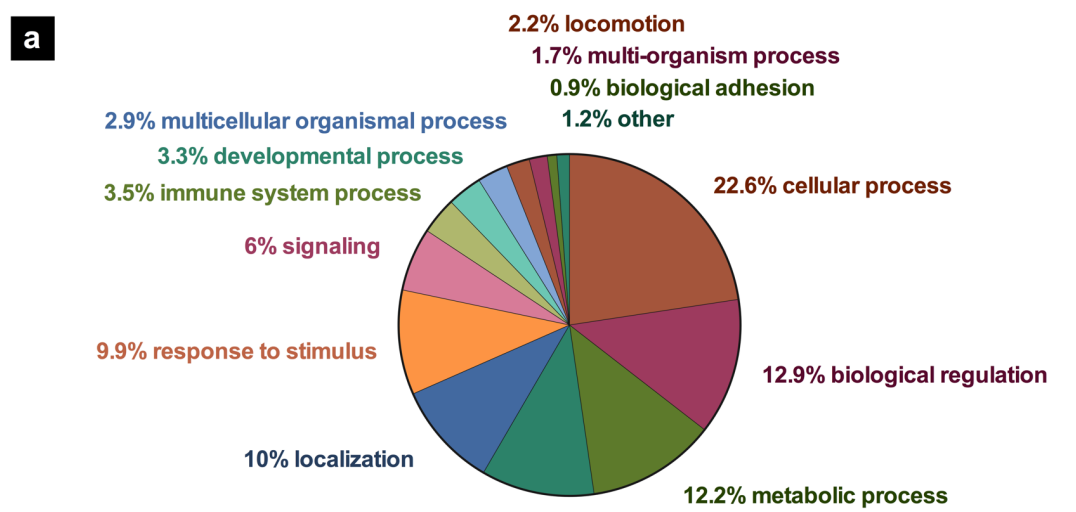

$10.7 \%$ cellular component organization or biogenesis

b

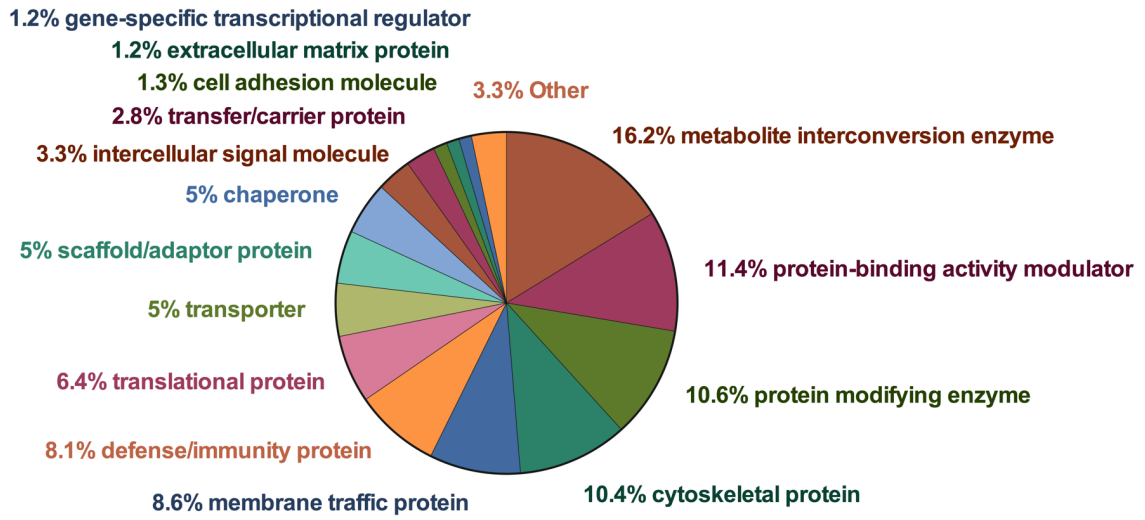

c

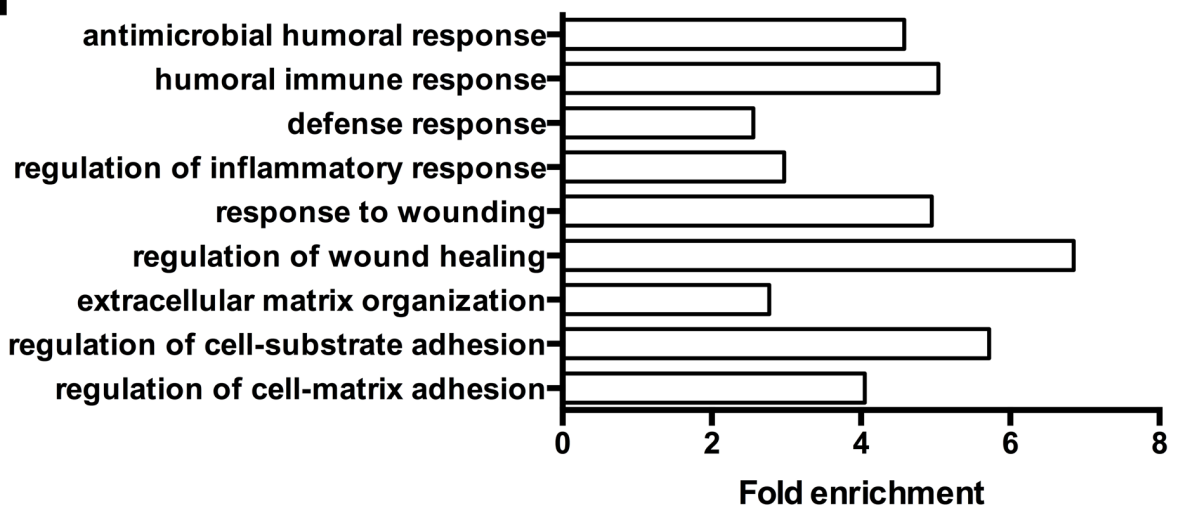

Figure 3. Proteomic analysis of the PL proteins adsorbed on CNC's surface. (a) Proteins organized according to their biological process categories. Categories with a representation lower than $0.9 \%$ were grouped in "other". The percentage $(\%)$ corresponds to the fraction of protein hits in a category against the total number of process hits; (b) Proteins organized according to their protein class. Categories with a representation lower than $1 \%$ were grouped in "other". The percentage (\%) corresponds to the fraction of protein hits in a category against 


\section{WILEY-VCH}

the total number of process hits; (c) Enrichment analysis of proteins involved in selected biological process categories against the human proteome $(\mathrm{p}<0.05)$.

We next studied how the coatings affected the surface properties since these can affect the implant biocompability and the cell-material interactions. ${ }^{[9]}$ The average surface roughness $\left(\mathrm{S}_{\mathrm{a}}\right)$ of Ti surfaces $(23 \mathrm{~nm})$ increased on Ti/CNC $(28 \mathrm{~nm})$ and Ti/CNC/PL surfaces $(34 \mathrm{~nm})$ (Figure 4a), which can be attributed to changes in surface topography produced by CNC deposition and further PL biomolecules adsorption. Previous studies have shown that fibroblasts adhesion and growth seems to be enhanced in smooth or finely grooved surfaces $\left(\mathrm{S}_{\mathrm{a}}\right.$ 25-100 nm) rather than on microrough surfaces $\left(S_{a} \sim 1 \mu \mathrm{m}\right) \cdot{ }^{[47]}$ Thus, we expect that, since the $\mathrm{S}_{\mathrm{a}}$ values observed in the present work remained in the same order of magnitude, the surface chemistry might play a more relevant role in the bioactivity of the surfaces. Furthermore, roughness at the nanoscale promotes protein adsorption, integrin-mediated cell attachment and the ability for the incorporation of growth factors. ${ }^{[9]}$

The wettability of the surfaces was assessed by contact angle measurements (Figure $4 \mathrm{~b}$ ). The results indicate that all surfaces were hydrophilic, with contact angle lower than $90^{\circ}$, which could facilitate the initial interactions of the implant with surrounding tissues, relevant for wound healing and tissue integration. ${ }^{[48]}$ The contact angle on $\mathrm{Ti}\left(29 \pm 14^{\circ}\right)$ increased upon CNC deposition $\left(58 \pm 9^{\circ}\right)$, probably due to the combination of CNC amphiphilic character ${ }^{[27]}$ and the different nanotopography resulting from $\mathrm{CNC}$ adsorption. ${ }^{[49]}$ Furthermore, the contact angle on $\mathrm{Ti} / \mathrm{CNC} / \mathrm{PL}\left(23 \pm 5^{\circ}\right)$ was the lowest, indicating that the presence of the PL proteins could partially mask CNC surface chemistry and that it has a considerable impact on the wettability of the surface. This is a positive effect for the proposed application because it has been shown that surfaces with enhanced wettability (lower contact angle) are associated with improved implant success. ${ }^{[48]}$ 


\section{WILEY-VCH}
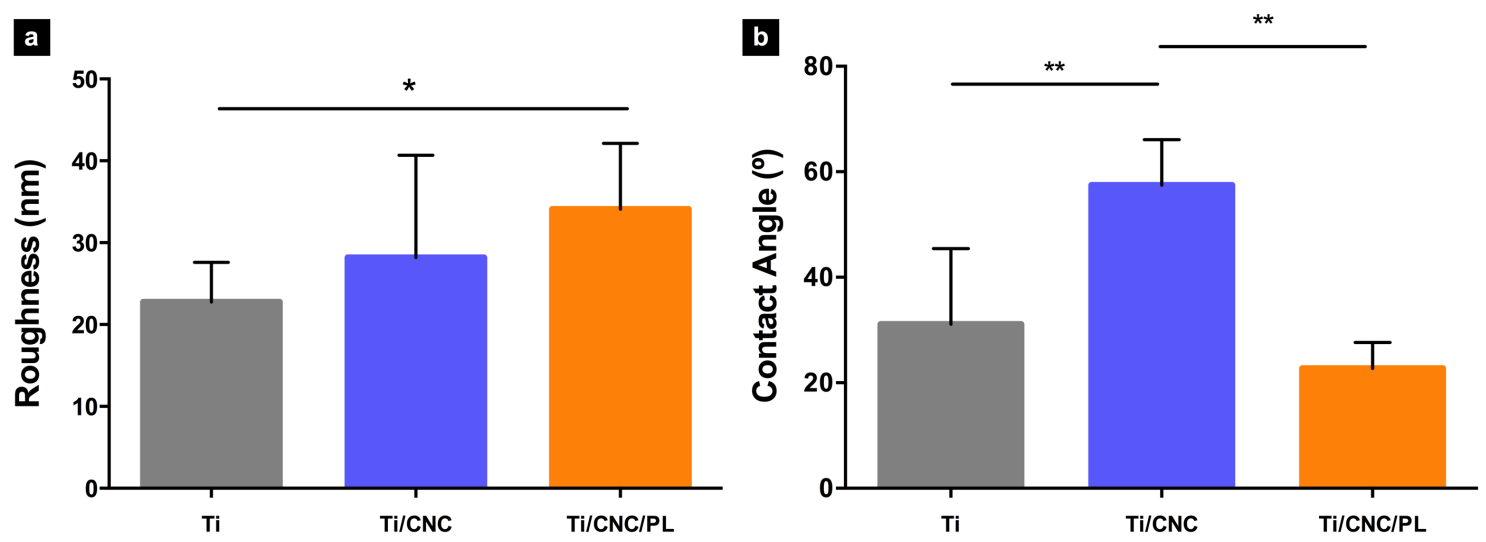

Figure 4. Characterization of surface roughness and wettability. (a) Average surface roughness of the coated surfaces and Ti control surface $(n=9 ; * p<0.05)$. (b) Contact angle measurements of the different coated surfaces and Ti control surface $(\mathrm{n}=4 ; * * \mathrm{p}<0.01)$.

\subsection{Orientation of biofunctionalized CNC nanopatterns controls the cell organization}

In order to evaluate the potential of the PL-functionalized anisotropic surfaces on orienting cell organization, primary human gingival fibroblasts (HGF) were used for cell culture since they represent the vast majority of cells in gingival soft tissue and play an active role during soft tissue integration of dental implants. ${ }^{[50]}$ First, we analyzed the cellular proliferation and morphology on Ti compared with Ti/CNC/PL-functionalized random and aligned surfaces. As can be seen in Figure 5a, cells cultured on the different surfaces were proliferating over time without significant differences between groups. These results indicate that the surfaces with different compositions and topographies are not cytotoxic and support cellular growth. Then, the effect of nanotopography on cell elongation was investigated by measuring cells' aspect ratio. Due to cell overlapping, only samples cultured for 1 and 3 days were analyzed. After only 1 day of culture, HGF started to acquire the typical spindle-shape morphology on all surfaces, as indicated by a high cell aspect ratio (Figure 5b). Overtime, although cells aspect ratio increased on all tested conditions, we observed a higher difference between 1 and 3 days on random and aligned surfaces than on Ti. Particularly on the aligned surfaces, the aspect ratio 


\section{WILEY-VCH}

was significantly higher than on random and Ti surfaces at both time points, probably due to the polarization of the cells in the direction of the $\mathrm{CNC}$ alignment (Figure 5b). These findings agree with previous works showing that surfaces with anisotropic nanotopographies (ridges and grooves) ${ }^{[51]}$ or coated with oriented cellulose nanowhiskers ${ }^{[15,16]}$ induced cell elongation (high aspect ratio) and contact guidance of osteosarcoma cells and myoblasts, respectively.

Next, the alignment of cells' cytoskeleton was analyzed over time (Figure 5c-e). During the first 7 days of culture, it was possible to observe a preferential cell orientation on the aligned surfaces, consistent with the effects resulting from nanotopographical contact guidance. ${ }^{[15,16,51]}$ Although not all the cells are oriented in the same specific direction as the approximate local radial axis, it is possible to observe lower cell order on the Ti control and random surfaces than on aligned surfaces (Figure 5c). These observations were confirmed by cytoskeleton directionality analysis (Figure 5d). While histograms showing flat distributions are observed on both isotropic surfaces ( $\mathrm{Ti}$ and random), indicating a lower degree of orientation, narrow distributions with sharp peaks were obtained for the aligned surfaces, indicating higher degree of orientation. These data were confirmed with the Gaussian distribution fitting (Figure 5e), which showed FWHM values for aligned surfaces lower $\left(\mathrm{FWHM} \approx 50^{\circ}\right)$ than for the random samples $\left(\mathrm{FWHM} \approx 150^{\circ}\right)$.

The directionality of the cell's distribution was further evaluated for 14 and 21 days of culture. On the aligned surfaces, we observed a higher cytoskeleton orientation with a narrower peak distribution than on random surfaces (Figure 5d). However, compared with earlier time points, the height of the peaks is shorter, indicating less cells showing a preferential orientation, and the FWHM value is higher, indicating a wider distribution of orientation directions. These results indicate that the orientation effect of the aligned nanopatterns tends to be lost with time. Since with proliferation over time (Figure 5a) HGF start to form multilayers (as observed in Figure 5c), we hypothesize that cells on the upper layers loose the topographical reference provided by the nanopatterned surfaces. Although in future studies it would be interesting to 


\section{WILEY-VCH}

study the synergy of the anisotropic CNC nanopatterns and microscale patterns (created by e.g. machining, laser ablation) to guide HGF in multiple layers, the results suggest the potential of anisotropic $\mathrm{CNC}$ deposition to recreate the topographical cues of native anisotropic extracellular matrix environments.

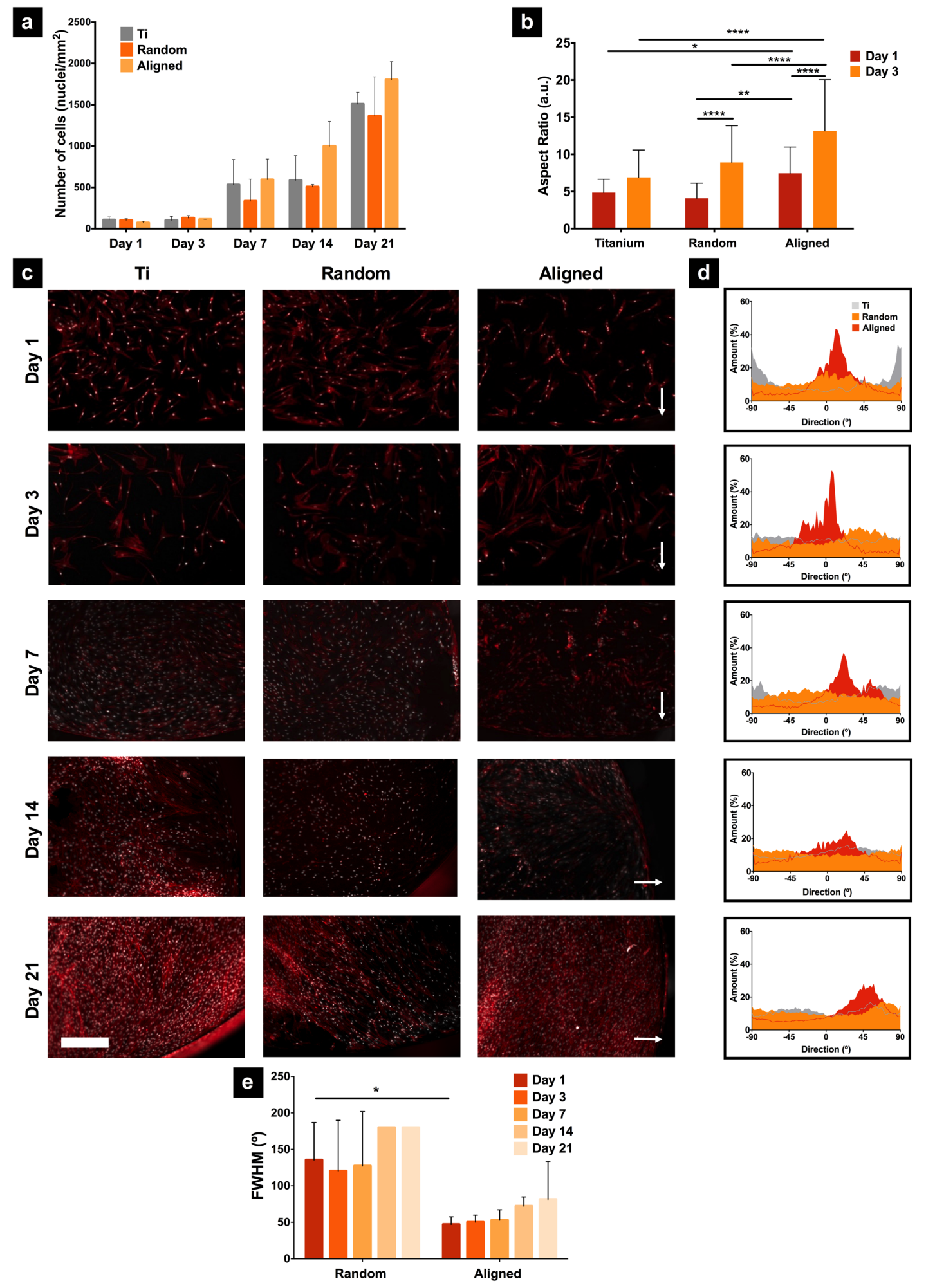




\section{WILEY-VCH}

Figure 5. Cell adhesion, morphology and directionality on $\mathrm{Ti}$ and $\mathrm{Ti} / \mathrm{CNC} / \mathrm{PL}$ random and aligned surfaces. (a) Number of cells on the surfaces cultured for 1, 3, 7, 14 and 21 days $(n=4)$.

(b) Aspect ratio of cells cultured on the surfaces for 1 and 3 days $\left(\mathrm{n}=4 ;{ }^{*} \mathrm{p}<0.05 ;{ }^{*} \mathrm{p}<0.01\right.$; $* * * * \mathrm{p}<0.0001)$. (c) Fluorescence microscopy images of HGF on the different surfaces stained for cytoskeleton (red) and nuclei (white). Scale bar: $200 \mu \mathrm{m}$. Arrows indicate the approximate local radial axis. (d) Directionality histograms from representative images of florescence microscopy images. (e) FWHM of the histograms determined by Gaussian fitting of the curves $(\mathrm{n}=3 ; * \mathrm{p}<0.05)$

\subsection{Biofunctionalization improves the cell-scale interactions with the implant surfaces}

The cell-scale interactions with the biofunctionalized implant surfaces, which are crucial to improve cell adhesion and soft tissue integration, were investigated. Cell adhesion occurs through the formation of supramolecular protein complexes called focal adhesions, which are nanoscale $(<200 \mathrm{~nm})$ networks of transmembrane integrins and cytoplasmic proteins that form a bridge between the ECM proteins and the actin cytoskeleton. ${ }^{[52]}$ We analyzed the expression of vinculin (Figure 6a), a key protein to stabilize the focal adhesion complex. ${ }^{[52]}$ Cells showed vinculin expression on PL-nanocoated surfaces and Ti control. Although the expression of vinculin was mainly cytoplasmatic, we observed some mature and well-developed focal adhesions plaques at the cell's filopodia, especially on biofunctionalized surfaces. In order to confirm these results, the number of filopodia per cell was also quantified (Figure 6b). We found that cells on PL-nanocoated surfaces showed a higher number of filopodia than on $\mathrm{Ti}$ control surfaces. Filopodia have a key role in substrate tethering, recognition of ECM topography and environment sensing. ${ }^{[53]}$ Although Ti has been shown to support adhesion and growth of different cell types, ${ }^{[1]}$ our findings may be related to the presence of ECM proteins and cell-adhesion cues from PL, including fibronectin and vitronectin (Table S1, Supporting Information). We hypothesize that these proteins interacted with cells' integrins favoring the 


\section{WILEY-VCH}

formation of more filopodia, as previously shown using surfaces coated with fibronectin, which promoted fibroblast adhesion and the assembly of focal adhesions. ${ }^{[54,55]}$ Moreover, previous studies have shown that the elongation of cells and the formation of filopodia was enhanced in the direction of $\mathrm{CNC}$ alignment, ${ }^{[16]}$ which may be related to the slightly higher number of filopodia on aligned PL-functionalized surfaces. Therefore, the results of the present work suggest that PL-biofunctionalization might be used as a simple strategy to improve cell adhesion not only to metal implants but also multiple surfaces and synthetic tissue engineering scaffolds.
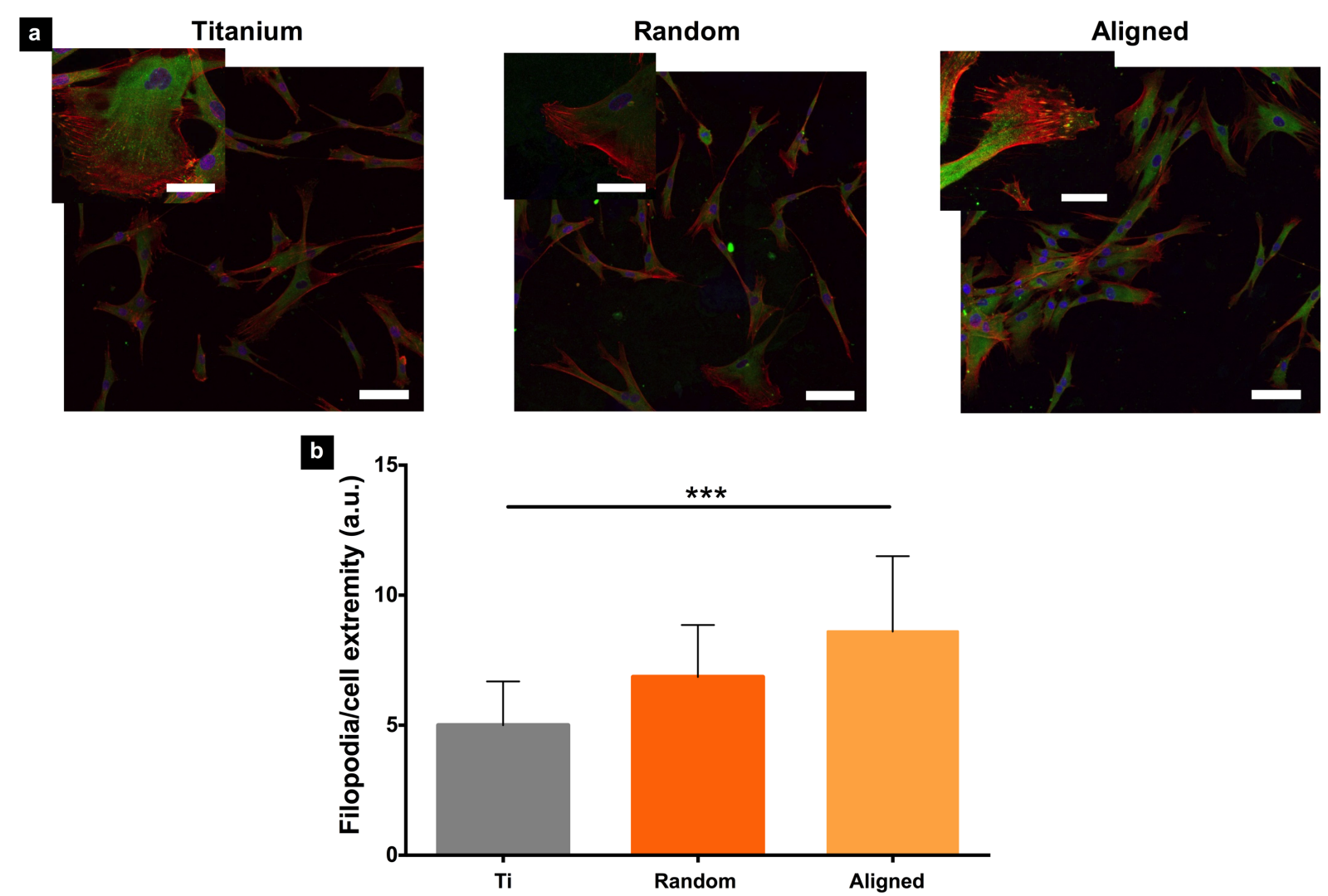

Figure 6. Cell adhesion to the biofunctionalzed surfaces. (a) Confocal images of fibroblasts cultured for 3 days on $\mathrm{Ti}$ and $\mathrm{Ti} / \mathrm{CNC} / \mathrm{PL}$ random and aligned surfaces, stained for vinculin (green), cytoskeleton (red), and nuclei (blue). Scale bar: $75 \mu \mathrm{m}$; inset $25 \mu \mathrm{m}$. (b) Quantification of the number of filopodia per cell extremity $(n=3 ; * * * p<0.001)$.

\subsection{Biofunctionalized surfaces promote pro-regenerative inflammatory response}




\section{WILEY-VCH}

The typical surgical placement of a metallic implant inevitably results in the activation of the host immune response. This is particularly relevant for dental implants since they are placed in the oral cavity, under constant attack by bacteria, chemical substances, and physical damage. ${ }^{[8]}$ Macrophages are responsible for the initial immune response, clearing apoptotic cells, tissue debris and bacteria, and producing signals to recruit support cells to amplify the inflammatory reaction or to attenuate it and promote tissue healing and regeneration. This is mainly mediated by the balance between pro-inflammatory M1 macrophages and antiinflammatory M2 macrophages. ${ }^{[56]}$ It has been previously shown that macrophage behavior can be affected by biomaterial properties such as surface topography, porosity and release of proteins. ${ }^{[57-59]}$ In order to study macrophages response to the developed surfaces, cells were stained with the specific markers CCR7 and CD206 to identify M1 and M2 macrophages phenotypes, respectively (Figure 7a-b). We observed that Ti control surfaces as well as Ti/CNC surfaces, presented a higher number of M1-like macrophages (CCR7+) and a lower number of M2-like macrophages (CD206+) compared with Ti/CNC/PL. To substantiate these observations, we quantified the area stained by the specific macrophage phenotypes markers per nuclei (Figure 7c). The results showed that PL-nanocoated surfaces induced higher polarization towards the anti-inflammatory M2-like phenotype and decreased the presence of M1-like macrophages compared with $\mathrm{Ti}$ and $\mathrm{Ti} / \mathrm{CNC}$. In fact, the M1/M2 ratio on $\mathrm{Ti}, \mathrm{Ti} / \mathrm{CNC}$ and $\mathrm{Ti} / \mathrm{CNC} / \mathrm{PL}$ surfaces was $\sim 1400,50$ and 5 , respectively, confirming the preferential M2like phenotype on PL functionalized surfaces. These results may be supported and correlated with findings of the proteomic analysis, which revealed the presence of different growth factors and cytokines with potential roles in the modulation of inflammatory response (Table S1, Supporting Information). Among these, TGF- $\beta 1$ has been shown to play a critical role enhancing the M2 anti-inflammatory macrophage activation. ${ }^{[59,60]}$ Furthermore, surface topography and wettability are able to modulate macrophages polarization. ${ }^{[59,61]}$ Previous studies have demonstrated that whereas smooth Ti surfaces induced the pro-inflammatory 


\section{WILEY-VCH}

macrophage (M1-like) activation, rougher Ti surfaces promoted an anti-inflammatory M2-like state. ${ }^{[59]}$ We hypothesize that, in the present work, the biochemical signals from PL nanocoating, together with the adequate roughness and the hydrophilic character of Ti/CNC/PL surface, might have collectively favored the polarization of macrophages towards the anti-inflammatory phenotype, which in turn may potentially yield a more suitable microenvironment for implant integration success.
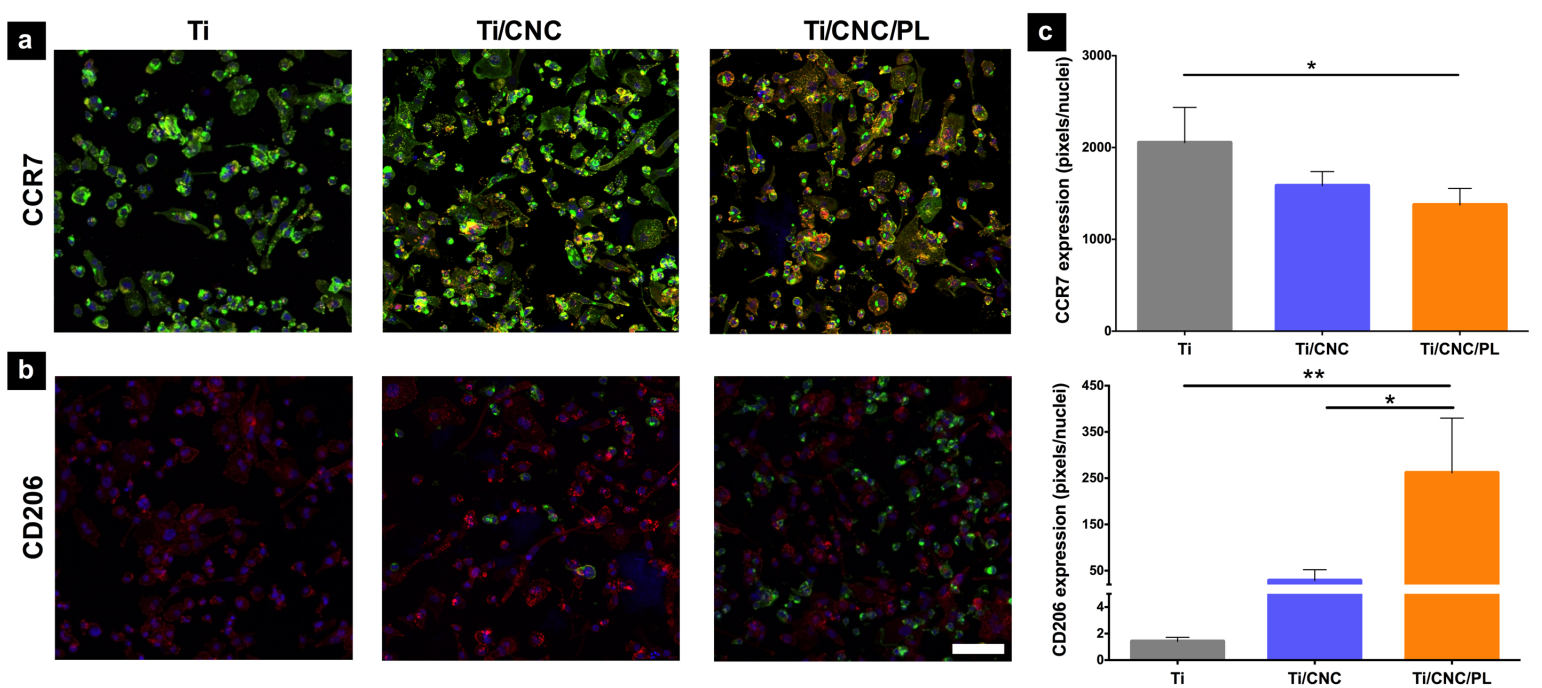

Figure 7. Macrophages polarization assay. Cells were immunostained with (a) anti-CCR7 (M1like) or (b) anti-CD206 (M2-like), which appears in green, while nuclei and cytoskeleton appear in blue and red, respectively. Scale bar: $100 \mu \mathrm{m}$. (c) Quantitative analysis of the area stained in green corrected by the number of cells for each marker $\left(n=3 ;{ }^{*} p<0.05\right)$.

\section{Conclusion}

Currently, there is a high demand to improve metal implants-soft tissue integration in clinical applications. Herein, we propose a multifunctional surface coating strategy based on the introduction of biophysical and biological cues to tackle this need and improve implants performance. By spinning rod-shaped $\mathrm{CNC}$ at high-speed, we were able to create anisotropic nanopatterns on $\mathrm{Ti}$ surfaces, which was confirmed by image directionality analysis. Simultaneously CNC acted as intermediates for the binding of proteins derived from PL. The 


\section{WILEY-VCH}

sequestration of multiple bioactive molecules on implant surfaces was confirmed using QCM$\mathrm{D}$ and proteomic analysis, which revealed the formation of a coating composed of molecules related to cell adhesion, would healing, inflammatory response and antimicrobial response, among others. These surfaces induced human gingival fibroblasts stretching and guided their orientation in the direction of the $\mathrm{CNC}$ ordered axis, as confirmed by cell cytoskeleton directionality analysis. Moreover, these surfaces polarized naïve macrophages towards the antiinflammatory M2 phenotype. Taken together, the proposed system holds a great potential to provide a tighter soft tissue seal around metal implants due to cell alignment around the surface and, at the same time, to prevent bacterial invasion, tissue inflammation, loosening and failure of the biomedical metallic implants.

\section{Materials and Methods}

\subsection{Titanium samples preparation}

Coin-shaped samples (diameter of 6.2, height of $2 \mathrm{~mm}$ ) made of grade IV commercially pure titanium (Ti) were polished and washed as previously described. ${ }^{[62]}$ Coins were stored in $70 \%$ ethanol at room temperature (RT). Before use, Ti coins were dried with nitrogen gas and exposed to UV radiation for 15 min under ambient conditions, using a UV/ozone cleaner (ProCleaner, Bioforce, USA).

\subsection{Production of isotropic and anisotropic nanopatterned surfaces}

Cellulose nanocrystals (CNC) were extracted by acid hydrolysis of the amorphous regions of cellulose microfibrils (microcrystalline cellulose powder, Avicel PH-101) accordingly to our previously described procedure, resulting in the characteristic rod-shaped nanoparticles bearing anionic sulfate ester groups at their surface. ${ }^{[31]}$

A spin coater (WS-650-23, Laurell Technologies, USA) was used to produce Ti/CNC nanopatterned surfaces, according to previous publications with minor modifications. ${ }^{[16]}$ First, 


\section{WILEY-VCH}

an aliquot $(70 \mu \mathrm{L})$ of polyethylenimine (PEI, Sigma-Aldrich, USA, high molecular weight and branched, $20 \mathrm{mM}$ in $0.5 \mathrm{M} \mathrm{KCl}$ ) was dropped onto the Ti samples and then accelerated to 2000 rpm. After $30 \mathrm{~s}$, the samples were washed twice with ultrapure water at $500 \mathrm{rpm}$ during $10 \mathrm{~s}$. Afterwards, the samples were dried gently under a steady nitrogen stream. To prepare the nanopatterns with lower degree of radial orientation (random), the $\mathrm{CNC}$ suspension $(70 \mu \mathrm{L}$, $0.01 \% \mathrm{w} / \mathrm{v}$ ) was dropped onto the stationary sample, and the adsorption was allowed to take place for $20 \mathrm{~s}$ with an acceleration of $500 \mathrm{rpm}$. The samples were then accelerated to $3000 \mathrm{rpm}$ for $20 \mathrm{~s}$. To prepare the CNC surfaces with high degree of radial orientation (aligned), the spin speed was increased to $6000 \mathrm{rpm}$, and $10 \mathrm{~s}$ later the $\mathrm{CNC}$ suspension $(70 \mu \mathrm{L}, 0.01 \% \mathrm{w} / \mathrm{v})$ was dropped onto the sample. After 10 seconds, the spin speed was lowered to $3000 \mathrm{rpm}$ for $20 \mathrm{~s}$ to dry the sample. The samples were dried overnight at $60^{\circ} \mathrm{C}$.

\subsection{Nanocoating of the nanopatterned surfaces with platelet lysate}

Platelet lysate (PL) used in the present study was obtained from a pool of 16 platelet concentrates units, each unit containing platelets from 5 donors, therefore, a total 80 donors. Platelet concentrates were provided by Centro Hospitalar de São João (Porto, Portugal) under an approved institutional board protocol (Hospital ethical commission approval number 363/18). All the units were submitted to three freeze/thaw cycles, as previously described ${ }^{[25]}$. Briefly, platelet units were thawed at RT and pooled. In order to promote platelet lysis and the subsequent release of their content, the platelet pools were subjected to three cycles of thawing at $37^{\circ} \mathrm{C}$ followed by freezing with liquid nitrogen, and stored at $-80{ }^{\circ} \mathrm{C}$. Right before use, PL was thawed, centrifuged at $4000 \mathrm{x} \mathrm{g}$ for $5 \mathrm{~min}$ and filtered through a $0.45 \mu \mathrm{m}$ pore filter to remove any cell debris or clots.

To produce the PL nanocoatings on $\mathrm{Ti} / \mathrm{CNC}$, these samples were washed with ultrapure water during 5-10 min under continuous stirring, and subsequently left to dry for $1 \mathrm{~h}$ at $60^{\circ} \mathrm{C}$. Then, the samples were washed twice with phosphate buffered saline (PBS; ThermoFisher 


\section{WILEY-VCH}

Scientific, USA) and sterilized using UV-light for $20 \mathrm{~min}$. Afterwards, the samples were rinsed with sterile PBS and placed into sterile 24-well culture plates. The samples were incubated with PL for $1 \mathrm{~h}$ at $37^{\circ} \mathrm{C}$ under constant agitation (180-200 rpm) and subsequently washed three times with sterile PBS, under sterile conditions. Unless otherwise stated, Ti/CNC/PL samples were used right after the PL coating.

\subsection{Characterization of nanocoated surfaces}

\subsubsection{Atomic force microscopy}

The nanopatterns present on the developed surfaces were revealed by AFM. Using the digital camera of the AFM, the borders and center of the sample were visualized and high magnification scans at those specific locations were taken. The scans were collected in tapping and contact mode. Triangular silicon AFM cantilevers (ScanAsyst-Air, Bruker) were used, with spring constants of $6 \mathrm{~N} / \mathrm{m}$ and frequency of $150 \mathrm{kHz}$. Three scans from three independent samples from each group were collected and analyzed with NanoScope (version 1.5) to generate the $2 \mathrm{D}$ and $3 \mathrm{D}$ projections.

\subsubsection{Directionality}

The directionality of the nanopatterns created with $\mathrm{CNC}$ was evaluated from images acquired from AFM. For that purpose, the directionality plugin from ImageJ software (version: $1.50 \mathrm{~b}, \mathrm{NIH}, \mathrm{USA}$ ) was used. Initially, the images from AFM were divided in color channels, to increase $\mathrm{CNC}$ contrast, and the green channel was used to obtain the directionality histograms and dispersion of the directions. One image from center and border from 3 different samples were rotated according to the direction that was expected on that portion of the surface to obtain comparable histograms. The resulting histograms were fit to the Gaussian distribution function using Origin (OriginLab Co, USA) and the FWHM of the fitted curve was determined for each sample. When the histograms did not fit to a Gaussian distribution (adjusted R-square $<0.8$ ), we manually assigned values of FWHM $=180^{\circ}$, as previously described. ${ }^{[63,64]}$ At least three 


\section{WILEY-VCH}

images per condition were considered and a representative histogram for each condition was plotted.

\subsubsection{PL coating formation}

PL coating formation was investigated in real time by means of a quartz crystal microbalance with dissipation monitoring (QCM-D; Q-Sense, Biolin Scientific). The QCM sensors (Ti/Au AT-cut quartz sensors, AWSensors, Spain) were cleaned according to the manufacturer's procedure. Then, the sensors were nanocoated with $\mathrm{CNC}$ using the procedure described before but adjusting the volume of the solutions to $100 \mu 1$. The freshly prepared PL solutions were deposited on bare and CNC-coated QCM sensors, using a flow system. The procedure was repeated three times. First, a PBS solution was pumped over the quartz crystals at flow rate of $100 \mu \mathrm{L} / \mathrm{min}$, and 2 min later shifted to the PL coating solution (different dilutions were first tested, i.e. $0,25,50$ and $75 \%$ PL in PBS), at flow rate of $10 \mu \mathrm{L} / \mathrm{min}$. After this, a rinsing step with PBS at a flow rate $0.1 \mathrm{~mL} / \mathrm{min}$ was performed for $30 \mathrm{~min}$. During coating deposition, changes in resonance frequency $(\Delta \mathrm{f})$ and dissipation factor $(\Delta \mathrm{D})$ were constantly monitored. The obtained data of the third, fifth, and seventh harmonic are presented in two different ways: either versus time $(\Delta \mathrm{f}-\mathrm{t}$ and $\Delta \mathrm{D}-\mathrm{t}$ plots $)$ or as $\Delta \mathrm{D}$ versus $\Delta \mathrm{f}(\Delta \mathrm{D}-\Delta \mathrm{f}$ plots $)$.

\subsubsection{Profilometry}

Topographical properties of the surfaces were characterized using a 3D Optical Profilometer (Sensofar S Neox, Spain). The profilometer scans were projected on SensoSCAN 6.3 program and the surface amplitude parameters were calculated with SensoMap Standard 6.3 software. To calculate Sa, each surface (three coins per group) was scanned ( 255 x $191 \mu \mathrm{m})$ on three different areas of the surface.

\subsubsection{Contact Angle}

A goniometer (OCA 15+, DataPhysics Intruments, Germany) was used with sessile drop (needle in) mode at RT to measure the contact angle. Two coins from each group and two areas of each were measured with $0.5 \mu \mathrm{L}$ ultrapure water. 


\section{WILEY-VCH}

\subsubsection{Proteomic analysis}

To study the proteins absorbed on the CNC, mass spectrometry-based proteomic analysis was performed as previously reported. ${ }^{[17]}$ Briefly, equal volumes of $\mathrm{CNC}$ solutions diluted with ultrapure water to a final concentration of $2 \mathrm{mg} / \mathrm{mL}$ (containing $3.8 \mathrm{mg}$ of $\mathrm{CNC}$ ) and $\mathrm{PL}$ (containing $128.44 \mathrm{mg}$ of total protein content) were incubated for $60 \mathrm{~min}$ at $37{ }^{\circ} \mathrm{C}$ under constant agitation $(200 \mathrm{rpm})$. CNC were separated from the supernatant by centrifugation at $15000 \times \mathrm{g}$ for $30 \mathrm{~min}$. The nanoparticle pellet was resuspended in PBS and washed by three centrifugation steps at $15000 \times \mathrm{g}$ for $30 \mathrm{~min}$, and subsequently redispersed in $60 \mu \mathrm{L}$ of ultrapure water and frozen until further analysis. Three independent samples were used. After protein identification and quantification, the raw data was processed using Proteome Discoverer 2.4.0.305 software (ThermoFisher Scientific) and searched against the UniProt database for the Homo sapiens Proteome 2019_09. The identified proteins were grouped according to the protein analysis through evolutionary relationships (PANTHER) classification system according to gene ontology (GO) biological process categories and protein class (http://www.pantherdb.org/, version 15.0). Then, a Panther Overrepresentation test (released 20200407) using Fisher's Exact test with Bonferroni correction for multiple testing was performed for the identified proteins.

\subsection{Biological in vitro evaluation using human gingival fibroblasts}

\subsubsection{Cell culture}

Primary human gingival fibroblasts (HGF) were purchased from Provitro AG (Germany). Cells were routinely cultured at $37{ }^{\circ} \mathrm{C}$ and $5 \% \mathrm{CO}_{2}$, and maintained in fibroblasts growth medium (Provitro AG) supplemented with 10\% foetal bovine serum (FBS, ThermoFisher Scientific) and 1\% antibiotic/antimycotic solution (ThermoFisher Scientific). Experiments were performed with HGF between passages 2 and 4. 


\section{WILEY-VCH}

Samples were placed in $24-w e l l$ plates and $7.6 \times 10^{3}$ cells per well were seeded. At an initial phase, the cell culture medium was depleted from FBS to avoid exposure of the surfaces to FBS-derived proteins. After $2 \mathrm{~h}$, when the cells were adhered to the surfaces, and after 14 days, for the long-term culture, the culture media was supplemented with 1 and $10 \%$ (v/v) FBS, respectively. The medium was changed twice a week over the course of the different biological assays.

\subsubsection{Cell proliferation}

Nuclei counting at each time point was performed using ImageJ Analyze Particle (Ellipses) tool that automatically counted the number of nuclei. A pixel size $>10$ threshold was applied to remove background noise.

\subsubsection{Cell morphology}

Cells grown for 1, 3, 7, 14 and 21 days on the surfaces were fixed with neutral buffered formalin 10\% (v/v) (ThermoFisher Scientific) for $20 \mathrm{~min}$ and then washed twice with PBS. For cell nucleus and actin cytoskeleton filaments visualization, cells were stained with a solution of 4,6-diamidino-2-phenyindole dilactate (DAPI; Biotium, USA; 1:1000 v/v) and phalloidin tetramethylrhodamine B isothiocyanate (Phalloidin; Sigma-Aldrich, USA; 1:200 v/v) prepared in PBS for $30 \mathrm{~min}$ at RT and protected from the light. Samples were rinsed with PBS to eliminate excess dye. Four samples of each group were used to perform the experiment and several representative images were taken with a fluorescence microscope (Axio Imager Z1, Zeiss, Germany).

The cell aspect ratio (AR) was determined measuring the length and width of at least 50 different cells, from four images for each condition. Using ImageJ software, the length and width of each cell was manually plotted and the cell AR was calculated by dividing the length by the width.

\subsubsection{Cell directionality}




\section{WILEY-VCH}

The directionality of the cells was quantified from the fluorescence microscope images. The channel displaying the cytoskeleton was analyzed with directionality plugin from ImageJ. All images were rotated according to the direction of the $\mathrm{CNC}$ on that portion of the surface. At least 3 images per condition from two separate samples were analyzed, and a representative histogram for each condition was plotted.

\subsubsection{Vinculin immunostaining}

HGFs grown for 3 days on the different surfaces were used. Then, cells were washed with PBS, fixed with neutral buffered formalin 10\% (v/v) (ThermoFisher Scientific) for $20 \mathrm{~min}$ at RT and, finally, washed twice with PBS. Cells were permeabilised with $0.1 \%$ Triton X-100 for 10 min at RT, and then rinsed with PBS. All samples were blocked with $2 \%(w / v)$ bovine serum albumin (BSA) in PBS for $1 \mathrm{~h}$ at RT. Then, samples were incubated with a primary monoclonal mouse antibody against human vinculin (V9131, Sigma-Aldrich, 1:400 in 0.1\% BSA-PBS), overnight at $4^{\circ} \mathrm{C}$. Afterwards, samples were incubated with Alexa Fluor ${ }^{\circledR} 488$ donkey antimouse IgG secondary antibody (A21202, ThermoFisher Scientific, 1:200 in PBS) for $1 \mathrm{~h}$ at RT, protected from the light. Finally, all the samples were stained for cell cytoskeleton and nucleus, as previously described. Images were taken using a TCS SP8 confocal laser scanning microscope (Leica, Germany). The number of filopodia from 12-16 cells per group was counted manually from three independent high-magnification images. Filopodia were defined as cytoplasmic projections rich in actin staining.

\subsection{Macrophages polarization assay}

THP-1 cells (human leukemic monocytes) were obtained from the European Collection of Authenticated Cell Cultures (ECACC 88081201). Cells were routinely cultured in RPMI 1640 GlutaMAX medium (ThermoFisher Scientific) supplemented with 10\% (v/v) FBS (ThermoFisher Scientific) in a humidified 5\% CO2 atmosphere at $37^{\circ} \mathrm{C}$, following the supplier's instructions. The cells were maintained at a density of $3-8 \times 10^{5}$ cells $/ \mathrm{mL}$ by the 


\section{WILEY-VCH}

addition of fresh medium every 2 to 3 days. To induce macrophage differentiation, cells were seeded into UPcell culture plates $\left(35 \mathrm{~mm}\right.$, ThermoFisher Scientific) at a density of $1.1 \times 10^{5}$ cells $/ \mathrm{cm}^{2}$ and stimulated with $100 \mathrm{nM}$ phorbol-12-myristate 13-acetate (PMA; Sigma-Aldrich) for 1 day. Then, cells were washed with fresh medium and cultured for further $48 \mathrm{~h}$. Adhered M0 macrophages were then detached according to the UPcell culture plates manufacturer's instructions. The isolated cells were washed using basal medium and seeded onto the test surfaces at a density of $1.1 \times 10^{5}$ cells $/ \mathrm{cm}^{2}$ in culture media.

The polarization towards the pro-inflammatory M1-like phenotype or the antiinflammatory M2-like phenotype was evaluated after $24 \mathrm{~h}$ using the specific markers CCR7 and CD206, respectively. Cells were fixed and permeabilized as previously described. The samples were stained with specific primary antibody anti-CCR7 (1:250; rabbit IgG; Abcam, UK) or anti-CD206 (1:50; mouse IgG; SantaCruz Biotechnology, USA). Then the samples were incubated with secondary antibodies, donkey anti-rabbit IgG Alexa Fluor 488 (1/200; ThermoFisher Scientific) and rabbit anti-mouse IgG Alexa Fluor 488 (1/200; ThermoFisher Scientific), respectively. Afterwards, nuclei and cytoskeleton were stained using DAPI and Phalloidin, as previously described. The samples were visualized using confocal laser scanning microscope. Three images per group from three independent samples were analyzed using

ImageJ. A threshold was applied to each binarized channel to discard background pixels, and then the area of green pixels, corresponding to CCR7 or CD206 positively stained cells, was divided by the number of cells.

\subsection{Statistical Analysis}

Results are presented as mean values \pm SD (standard deviation). The statistical analysis of data was performed using GraphPad PRISM version 7.0. After testing for normality, oneway analysis of variance (ANOVA) followed by the Tukey post hoc test for multiple 


\section{WILEY-VCH}

comparisons was performed to compare groups of variables. Statistical significance was set to $\mathrm{p}<0.05$, represented by symbols described in the graphs.

\section{Supporting Information}

Supporting Information is available from the Wiley Online Library.

\section{Acknowledgements}

We acknowledge the financial support from International Team for Implantology - ITI Research grant 1306_2018; and from Fundação para a Ciência e a Tecnologia (FCT) for CEECIND/01375/2017.

Received: ((will be filled in by the editorial staff))

Revised: ((will be filled in by the editorial staff)) Published online: ((will be filled in by the editorial staff))

\section{References}

[1] S. Bauer, P. Schmuki, K. von der Mark, J. Park, Prog. Mater. Sci. 2013, 58, 261.

[2] M. N. Abdallah, Z. Badran, O. Ciobanu, N. Hamdan, F. Tamimi, Adv. Healthc. Mater. 2017, 6,1 .

[3] P. Datta, V. Vyas, S. Dhara, A. R. Chowdhury, A. Barui, J. Bionic Eng. 2019, 16, 842.

[4] E. Rompen, O. Domken, M. Degidi, A. E. F. Pontes, A. Piattelli, Clin. Oral Implants Res. 2006, 17 Suppl 2, 55.

[5] H. J. Busscher, H. C. Van Der Mei, G. Subbiahdoss, P. C. Jutte, J. J. A. M. Van Den Dungen, S. A. J. Zaat, M. J. Schultz, D. W. Grainger, Sci. Transl. Med. 2012, 4.

[6] G. Tsikandylakis, Ö. Berlin, R. Brånemark, Clin. Orthop. Relat. Res. 2014, 472, 2947. 


\section{WILEY-VCH}

[7] M. A. Atieh, N. H. M. Alsabeeha, C. M. Faggion, W. J. Duncan, J. Periodontol. 2012, 1.

[8] J. Derks, C. Tomasi, J. Clin. Periodontol. 2015, 42, S158.

[9] C. Mas-Moruno, B. Su, M. J. Dalby, Adv. Healthc. Mater. 2019, 8, 1.

[10] W. Teughels, N. Van Assche, I. Sliepen, M. Quirynen, Clin. Oral Implants Res. 2006, $17,68$.

[11] A. Civantos, E. Martínez-Campos, V. Ramos, C. Elvira, A. Gallardo, A. Abarrategi, ACS Biomater. Sci. Eng. 2017, 3, 1245.

[12] K. Gulati, H. J. Moon, P. T. S. Kumar, P. Han, S. Ivanovski, Mater. Sci. Eng. C 2020, 112, 110860.

[13] S. Lavenus, J. C. Ricquier, G. Louarn, P. Layrolle, Nanomedicine 2010, 5, 937.

[14] S. Namgung, K. Y. Baik, J. Park, S. Hong, ACS Nano 2011, 5, 7383.

[15] J. M. Dugan, J. E. Gough, S. J. Eichhorn, Biomacromolecules 2010, 11, 2498.

[16] J. M. Dugan, R. F. Collins, J. E. Gough, S. J. Eichhorn, Acta Biomater. 2013, 9, 4707.

[17] B. B. Mendes, M. Gómez-Florit, H. Osório, A. Vilaça, R. M. A. Domingues, R. L. Reis, M. E. Gomes, Chem. Commun. 2020.

[18] B. B. Mendes, M. Gómez-Florit, P. S. Babo, R. M. Domingues, R. L. Reis, M. E. Gomes, Adv. Drug Deliv. Rev. 2018, 129, 376.

[19] P. S. Babo, R. L. Reis, M. E. Gomes, J. Mater. Chem. B 2017, 5, 3617.

[20] R. Tejero, E. Anitua, G. Orive, Prog. Polym. Sci. 2014, 39, 1406.

[21] X. Wang, Y. Zhang, J. Choukroun, S. Ghanaati, R. J. Miron, Int. J. Mol. Sci. 2017, 18.

[22] N. E. Carlson, R. B. Roach, J. Am. Dent. Assoc. 2002, 133, 1383.

[23] S. M. Oliveira, V. E. Santo, M. E. Gomes, R. L. Reis, J. F. Mano, Biomaterials 2015, $48,56$.

[24] Q. Tang, T. Lim, X. J. Wei, Q. Y. Wang, J. C. Xu, L. Y. Shen, Z. Z. Zhu, C. Q. Zhang, Biomaterials 2020, 255. 


\section{WILEY-VCH}

[25] P. Babo, V. E. Santo, A. R. C. Duarte, C. Correia, M. H. G. Costa, J. F. Mano, R. L. Reis, M. E. Gomes, Inflamm. Regen. 2014, 34, 033.

[26] R. Costa-Almeida, A. R. Franco, T. Pesqueira, M. B. Oliveira, P. S. Babo, I. B. Leonor, J. F. Mano, R. L. Reis, M. E. Gomes, Acta Biomater. 2018, 68, 29.

[27] D. Klemm, E. D. Cranston, D. Fischer, M. Gama, S. A. Kedzior, D. Kralisch, F. Kramer, T. Kondo, T. Lindström, S. Nietzsche, K. Petzold-Welcke, F. Rauchfuß, Mater. Today 2018, 21, 720.

[28] M. S. Reid, M. Villalobos, E. D. Cranston, Langmuir 2017, 33, 1583.

[29] R. M. A. Domingues, M. E. Gomes, R. L. Reis, Biomacromolecules 2014, 15, 2327.

[30] D. Bondeson, A. Mathew, K. Oksman, Cellulose 2006, 13, 171.

[31] H. Almeida, R. M. A. Domingues, S. M. Mithieux, R. A. Pires, A. I. Gonçalves, M. Gómez-Florit, R. L. Reis, A. S. Weiss, M. E. Gomes, ACS Appl. Mater. Interfaces 2019, 11, 19830 .

[32] M. Jiang, S. N. Demass, D. R. Economy, T. Shackleton, C. L. Kitchens, J. Renew. Mater. 2016, 4, 377.

[33] R. Prathapan, R. F. Tabor, G. Garnier, J. Hu, ACS Appl. Bio Mater. 2020, 3, 1828.

[34] P. C. Ke, S. Lin, W. J. Parak, T. P. Davis, F. Caruso, ACS Nano 2017, 11, 11773.

[35] M. Rodahl, F. Höök, A. Krozer, P. Brzezinski, B. Kasemo, Rev. Sci. Instrum. 1995, 66, 3924.

[36] Y. Yao, K. Fukazawa, W. Ma, K. Ishihara, N. Huang, Appl. Surf. Sci. 2012, 258, 5418.

[37] M. J. Dalby, A. J. García, M. Salmeron-Sanchez, Nat. Rev. Mater. 2018, 3, 17091.

[38] S. P. B. Teixeira, R. M. A. Domingues, M. Shevchuk, M. E. Gomes, N. A. Peppas, R. L. Reis, Adv. Funct. Mater. 2020, 1909011, 1.

[39] S. Viau, A. Lagrange, L. Chabrand, J. Lorant, M. Charrier, K. Rouger, I. Alvarez, S. Eap, B. Delorme, Cytotherapy 2019, 21, 738.

[40] R. Crespo-Diaz, A. Behfar, G. W. Butler, D. J. Padley, M. G. Sarr, J. Bartunek, A. B. 


\section{WILEY-VCH}

Dietz, A. Terzic, Cell Transplant. 2011, 20, 797.

[41] M. M. Martino, P. S. Briquez, A. Ranga, M. P. Lutolf, J. A. Hubbell, Proc. Natl. Acad. Sci. U. S. A. 2013, 110, 4563.

[42] Y. Q. Tang, M. R. Yeaman, M. E. Selsted, Infect. Immun. 2002, 70, 6524.

[43] M. R. Yeaman, Cell. Mol. Life Sci. 2010, 67, 525.

[44] P. Y. Chung, R. Khanum, J. Microbiol. Immunol. Infect. 2017, 50, 405.

[45] B. B. Mendes, M. Gómez-Florit, A. C. Araújo, J. Prada, P. S. Babo, R. M. A.

Domingues, R. L. Reis, M. E. Gomes, Biomacromolecules 2020, 21, 3678.

[46] T. Burnouf, M.-L. Chou, Y.-W. Wu, C.-Y. Su, L.-W. Lee, Transfusion 2013, 53, 138.

[47] M. Gómez-Florit, J. M. Ramis, R. Xing, S. Taxt-Lamolle, H. J. Haugen, S. P.

Lyngstadaas, M. Monjo, J. Periodontal Res. 2014, 49, 425.

[48] F. Rupp, R. A. Gittens, L. Scheideler, A. Marmur, B. D. Boyan, Z. Schwartz, J. GeisGerstorfer, Acta Biomater. 2014, 10, 2894.

[49] M. Kulkarni, Y. Patil-Sen, I. Junkar, C. V. Kulkarni, M. Lorenzetti, A. Iglič, Colloids Surfaces B Biointerfaces 2015, 129, 47.

[50] P. C. Smith, C. Martínez, J. Martínez, C. A. McCulloch, Front. Physiol. 2019, 10.

[51] Q. Zhou, P. T. Kühn, T. Huisman, E. Nieboer, C. van Zwol, T. G. van Kooten, P. van Rijn, Sci. Rep. 2015, 5, 16240.

[52] J. L. Bays, K. A. DeMali, Cell. Mol. Life Sci. 2017, 74, 2999.

[53] G. Jacquemet, H. Hamidi, J. Ivaska, Curr. Opin. Cell Biol. 2015, 36, 23.

[54] G. Nardone, J. Oliver-De La Cruz, J. Vrbsky, C. Martini, J. Pribyl, P. Skládal, M. Pešl, G. Caluori, S. Pagliari, F. Martino, Z. Maceckova, M. Hajduch, A. Sanz-Garcia, N. M. Pugno, G. B. Stokin, G. Forte, Nat. Commun. 2017, 8, 15321.

[55] M. Chimutengwende-Gordon, C. Pendegrass, G. Blunn, Biomed. Mater. 2011, 6.

[56] D. M. Mosser, J. P. Edwards, Nat. Rev. Immunol. 2008, 8, 958.

[57] Claire E. Witherel, D. D. Abebayehu, P. T. H. Barker, P. K. L. Spiller, Adv Heal. 


\section{WILEY-VCH}

Mater 2019, 176, 139.

[58] R. Sridharan, A. R. Cameron, D. J. Kelly, C. J. Kearney, F. J. O’Brien, Mater. Today 2015, $18,313$.

[59] K. M. Hotchkiss, G. B. Reddy, S. L. Hyzy, Z. Schwartz, B. D. Boyan, R. OlivaresNavarrete, Acta Biomater. 2016, 31, 425.

[60] D. Gong, W. Shi, S. Yi, H. Chen, J. Groffen, N. Heisterkamp, BMC Immunol. 2012, 13,31 .

[61] M. A. Alfarsi, S. M. Hamlet, S. Ivanovski, J. Biomed. Mater. Res. - Part A 2014, 102, 60.

[62] S. F. Lamolle, M. Monjo, S. P. Lyngstadaas, J. E. Ellingsen, H. J. Haugen, J. Biomed. Mater. Res. - Part A 2009, 88, 581.

[63] S. Araújo-Custódio, M. Gomez-Florit, A. R. Tomás, B. B. Mendes, P. S. Babo, S. M. Mithieux, A. Weiss, R. M. A. Domingues, R. L. Reis, M. E. Gomes, ACS Biomater. Sci. Eng. 2019, 5, 1392.

[64] M. C. Echave, R. M. A. Domingues, M. Gómez-Florit, J. L. Pedraz, R. L. Reis, G. Orive, M. E. Gomes, ACS Appl. Mater. Interfaces 2019, 11, 47771. 


\section{WILEY-VCH}

\section{Table of contents}

To overcome the poor integration of metal implants to soft tissues, a multifunctional surface coating based on cellulose nanocrystals alignment and platelet-derived biomolecules sequestration is proposed. The combination of these biophysical and biological cues on a surface aligned fibroblasts and polarized macrophages toward an anti-inflammatory phenotype. These multifunctional surfaces might lead to implants with superior soft tissue integration abilities.

Adriana Vilaça, Rui M.A. Domingues, Hanna Tiainen, Bárbara B. Mendes, Alejandro Barrantes, Rui L. Reis, Manuela E. Gomes and Manuel Gomez-Florit*

Multifunctional surfaces for improving soft tissue integration

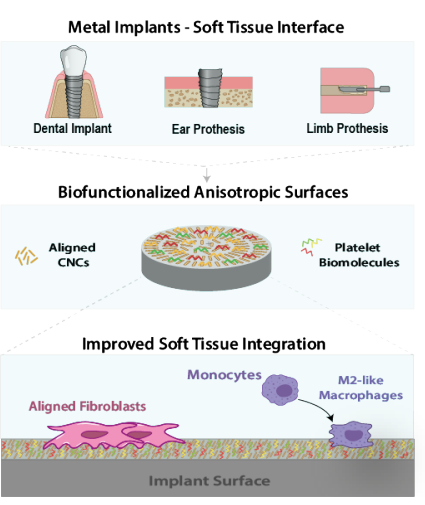

